2017-01-10

\title{
Digital Neighbourhoods: Hyperlocal Village Hubs in Rural Communities
}

Willis, Katharine S.

http://hdl.handle.net/10026.1/9199

10.1002/ad.2137

Architectural Design

Wiley

All content in PEARL is protected by copyright law. Author manuscripts are made available in accordance with publisher policies. Please cite only the published version using the details provided on the item record or document. In the absence of an open licence (e.g. Creative Commons), permissions for further reuse of content should be sought from the publisher or author. 


\section{Rural. Digital. \\ Hyperlocal village hubs}

City. Technology. The two are seen as analogous. If we imagine a busy city, we see citizens plugged into smartphones and tablets connected through social media, and in offices hyper connected networks of work stretch out globally. This vision of the city prioritises a globalised world, with mega urban centres. Yet, much of the world is predominantly rural, and even in the developed world the rural still plays crucial role in everyday life for many people, even if they don't actually live in rural towns or villages.

But those that live rurally have the potential to benefit most from the connectivity that the digital world brings. The vision of the rural idyll of a 'telecottage' may now be outdated, but the potential to have a high quality life locally whilst still being 'connected' globally still has appeal. Countering this vision is the argument that digital connectivity and online networks destroy all that is valuable about local community, by overrding face-to-face and local neighbourliness. But studies have shown that being connected online actually contributes to neighbourliness. Keith Hampton's study of a wired suburb found that wired residents were 2-3 times more likely than non-wired residents to recognise and talk with their neighbours and also had more contact with friends and relatives outside the neighbourhood ${ }^{1}$. This contributes to what is termed 'social capital' or the 'trust, norms and networks that can improve the efficiency of society by facilitating coordinated actions actions ${ }^{2}$, and in so doing it creates a new model of community that is not just about the geographical locality. In fact "useful approaches define community not in terms of locality, but as social networks of interpersonal ties that provide sociability, support, information, a sense of belonging, and social identity' ${ }^{3}$ (2002, p. 2). So, if we return to the rural context, we have the potential for villages and towns beyond the city to become enriched by online connections that overcome some of the geographical isolation that is seen as one of the downsides of living rurally.

In the Digital Neighbourhoods project at Plymouth University we attempted to find out and test what it means to be connected in a rural isolated village and what happens when you integrate online social networks with place-based networks. We put a particular focus on the spatial infrastructure that might provide a 'place' for technology, by linking up the rather ethereal world of online connections with the social meeting places for a local community.

Image 1 - neighbourhood

Caption:

You can have a community without having a neighbourhood, or maybe the other way around - you can have a neighbourhood without a community. A neighbourhood would be the geographical location, but the community is the way the people interact, respond, support and work together within that neighbourhood.

We worked with a series of small villages in rural Cornwall, in South West UK as part of a Superfast Cornwall Labs ${ }^{4}$; a programme delivering high speed broadband to rural communities. In our interviews and surveys with local people we found a pattern of connections that moved well beyond the perceived split between online

\footnotetext{
${ }^{1}$ Hampton, K. \& Wellman, B. 2003. Neighboring in Netville: How the Internet Supports Community and Social Capital in a Wired Suburb. City and Community 2, 277-311.

2 Putnam, R. 1993. The prosperous community: social capital and public life. American Prospect, 4.

${ }^{3}$ Wellman, B. Quan Hase, A., White, J. Hampton, K. (2001). Does the Internet Increase, Decrease, or Supplement Social Capital?: Social Networks, Participation, and Community CommitmentAmerican Behavioral Scientist November 45: 436-455

${ }^{4}$ http://www.superfastcornwall.org/programme/research-innovation
} 
connectivity and 'belonging' within a geographical place. In fact people in rural villages primarily used their online connections to reinforce a whole range of social connections; both locally but also nationally and even globally to keep in touch with a community that extended both locally but also around the world. But primarily connecting online was a way to reinforce village life way and to enable, reinforce, and extend existing connections to the village. So we saw a pattern of dense online, face-to-face and local connections though phone calls and texts that created a multilayered pattern of connections. But we also saw some people, notably gamers, who added in new connections online that were as meaningful to them as their friends and family and extended their sense of community well beyond the place where they lived.

Image 2- network connections

Caption:

Patterns of online and offline networks in a rural village. Central people provide dense patterns of connection, linking up the community into a dense network.

Image 3 - gamer

Caption:

Diagram of a social network of a village inhabitant who is an active online gamer (shown at the centre as a dot). The patterns of connection reveal local close connections to family and close friends (to the right), and global connections (to the left) to online gamer friends that create another scale and locality of community.

The key 'place' for technology in a rural community is the village hall. This is the venue that when it is digitally connected can create a hyperlocal hub. Village halls are the lifeblood of rural communities; they are where people meet, they host village fairs, yoga classes, parish councils, art groups and children's parties; they build and maintain social capital. We developed a series of digital interventions in the village hall in three rural villages in Cornwall that explored what happens when a local people connect both within and beyond their village.

Image 4-village hall

Caption

A digital village hall: Centre of Pendeen. Located in the village of Pendeen, close to Land's End in Cornwall, UK with around 900 residents. The Centre of Pendeen is a former snooker club that was refurbished and turned into a community centre which operates as a digital hub offering computer access, wifi and digital skills training

In November 2015 we organised an event that created a digital link up that was held simultaneously across four villages in Cornwall with a live video link up. Through a four way video conference set up villagers in the each of the village halls were able to see and talk to each other. In one village the patchwork group showcased their craft, whilst in another village the local history group explained how they had sourced and developed a book of local stories both online and offline. The potential of online live streaming is to create a sense of togetherness and reinforce locality through defining what people have in common and sharing experiences and local knowledge.

Image 5 - link up event

Caption :

Digital Village hall link up event. The 'hyperlocal' event created a the four way video link up across Cornwall with the villages of St Breward, Pendeen, St Dennis as well as Plymouth University.

Image 6- Facebook post/Facebook

Caption : 
Facebook post about link up event from the local Pendeen Patchwork group. 'Who'd have thought that Patchwork and digital technology have so much in common? Last Saturday's event at the Centre saw Pendeen's Patchwork Group take centre stage as we did a live video link up with Plymouth University and other Cornish village halls'

In summary, the rural is often overlooked in our focus on what digital connectivity can bring to communities, and although people never did and never will need technology to create, experience, and sustain community, technology can play a role in facilitating community. The unassuming village hall can be the 'place' where the digital, social and spatial bind together a sense of locality with the benefits of an online connectivity. This can do the vital job of enabling a sense of community that moves beyond 'community as a place' to 'community as a network' of hyperlocal connections. In our blinkered focus on the digital in the context of hyperconnected global cities we can potentially learn much from what it means to be locslly connected in a rural village. 